AperTO - Archivio Istituzionale Open Access dell'Università di Torino

Nymphal trophic behaviour of two Nemouridae species (Insecta, Plecoptera) in the Curone creek (northern Apennines, Italy)

This is a pre print version of the following article:

Original Citation:

Availability:

This version is available http://hdl.handle.net/2318/1728454 since 2020-02-19T10:48:28Z

Published version:

DOI:10.1111/j.1479-8298.2010.00392.x

Terms of use:

Open Access

Anyone can freely access the full text of works made available as "Open Access". Works made available under a Creative Commons license can be used according to the terms and conditions of said license. Use of all other works requires consent of the right holder (author or publisher) if not exempted from copyright protection by the applicable law. 
Short code: ENS

Title: Entomological Science

ISSN: 1343-8786

Created by: HN-PC43

Word version: 11.0

Email proofs to: manujlr@ugr.es

Copyright: @ 2010 The Entomological Society of Japan

Volume: (Issue: if known)

Cover year: 2010 (Cover month: if known)

Article no.: 392

Article type: OA (Original Article)

Figures: 2; Tables: 2; Equations: 0; References: 29; Words: 3116; First Page: 000; Last Page: 000

Short title running head: Nymphal diet of two Nemouridae species

Authors running head: M. J. López-Rodríguez et al.

Correspondence: Manuel Jesús López-Rodríguez, Dipartimento di Scienze dell'Ambiente e della Vita, Università del Piemonte Orientale, Via Teresa Michel, 11, 15121, Alessandria, Italy.Email: manujlr@ugr.es

Received 12 December 2009; accepted 16 March 2010.

ORIGINAL ARTICLE

\title{
Nymphal trophic behaviour of two Nemouridae species (Insecta, Plecoptera) in the Curone creek (northern Apennines, Italy)
}

\author{
Manuel J. LÓPEZ-RODRÍGUEZ ${ }^{1,2}$, Tiziano BO ${ }^{1}$, José M. T. de FIGUEROA² and Stefano FENOGLIO ${ }^{1}$ \\ ${ }^{1}$ Dipartimento di Scienze dell'Ambiente e della Vita, Università del Piemonte Orientale, Via Teresa Michel, \\ Alessandria, Italy; and ${ }^{2}$ Departamento de Biología Animal, Facultad de Ciencias, Universidad de Granada, Campus \\ Fuentenueva s/n, Granada, Spain
}

\begin{abstract}
Feeding habits of the Euholognathan stoneflies Nemoura hesperiae and Amphinemura sulcicollis are studied in a little stream located in northern Italy. The former fed mainly on coarse particulate organic matter (CPOM), together with detritus, while the latter fed principally on detritus and, in a lower concern, on CPOM. Thus they can be catalogued fundamentally as shredder and collector-gatherer, respectively. Shifts in diet composition were detected in relation to size in both taxa. Probably niche overlapping does not exist despite both species having similar size and nymphal development duration, and coinciding in time. This work supports that, though functional feeding groups are very useful, they should not be inferred from related species or higher taxonomical levels. Even intra-population differences and ontogenetic shifts should be considered in fine scale studies.
\end{abstract}

Key words: Amphinemura sulcicollis, diet, Nemoura hesperiae, ontogenetic shifts, southern Europe, stonefly.

\section{INTRODUCTION}

The study of feeding habits of macroinvertebrates is important to understand their role in the benthic community and their function in the metabolism. Lotic ecosystems depend on allochthonous and autochthonous organic inputs, and macroinvertebrates play a key role in the consumption of periphyton, aquatic plants, fine and coarse detritus (Monakov 2003); for example, these organisms represent one of the most important elements in running water food webs, because they ingest huge amounts of terrestrial leaves enhancing the energetic balance of the whole system (Fenoglio \& Bo 2009).

In stream ecology studies, there is a consolidate tendency to group macroinvertebrates into five Functional Feeding Groups (FFG) according to Merritt and Cummins (1996): scrapers, that remove biofilm and associated algae from various substrates; shredders, that ingest coarse particulate organic matter, mainly leaves; collectors-gatherers, that feed on fine sediments; filterers, that collect drifting organic particles; and predators. In origin, morphology of mouthparts and phylogenetic position played a main role in the assignation of organisms to the different FFG, but 
recently different studies underlined that is not always the morphology of mouthparts in animals that determines their feeding mechanisms and, consequently, that the feeding behaviour, even of similar species, may vary substantially (Monakov 2003). Thus, it is extremely important to study each single species to properly include them in the actual functional feeding group (sensu Merritt \& Cummins 1996) to which they belong. This is one of the first steps from which further ecological studies should be built. Furthermore, one of the most important works about trophic behaviour (Mihuc \& Minshall 1995) underlined that ecological studies in streams and rivers should be based at the species level.

Plecoptera is a very important order of aquatic insects in small lotic systems (Stewart \& Stark 2002). These hemimetabolous insects play a key role at different nodes of the trophic network in most temperate low order environments, acting as decomposers of allochthonous inputs, top predators and, in some cases, herbivores, feeding mainly on diatoms (Fochetti \& Tierno de Figueroa 2008a; Fenoglio \& Bo 2009). Particularly Nemouridae is considered one of the most diverse families in the order Plecoptera, with more than 600 described species (Fochetti \& Tierno de Figueroa 2008a).

In this work we study two stonefly species belonging to the family Nemouridae, Nemoura hesperiae Consiglio, 1960 and Amphinemura sulcicollis Stephens, 1836, which cohabit in the same creek.

Nemoura hesperiae is an endemic species of Italy present in low order streams of the Apennines and in the hydrographic network of Sicily (Fochetti \& Tierno de Figueroa 2008b). The nymph of this stonefly has been recently described by the authors from specimens collected in the same study site (Tierno de Figueroa et al. 2009). The flight period of this species is mainly spring in the study area (Bo et al. 2009).

Amphinemura sulcicollis is, however, a widely distributed species in Europe, which inhabits rivers of various orders and also lakes (Fochetti \& Tierno de Figueroa 2008b). This species has also a spring flight period in the study site (Bo et al. 2009), mainly coincident with the one of Nemoura hesperiae. The diet of this species has been previously reported in two classical articles by Hynes $(1941,1961)$ who found that A. sulcicollis nymphs were herbivorous and fed mainly on leaves, mosses, detritus and algae. Brinck (1949) recorded that in Swedish lotic systems, this species ingested mainly diatoms, higher plant and moss tissues, but also filamentous green algae, detritus and mineral matter. Also in northern Europe, Madsen (1974) showed that this species was detritivorous and ingested also a great amount of fungi.

Both species have a univoltine life cycle in the study site, and they cohabit and develop during approximately the same months of the year (Tierno de Figueroa et al. 2009).

In this study the gut content of $N$. hesperiae is analyzed for the first time, and trophic preferences of A. sulcicollis in the Curone creek are also reported and compared with results from studies in other areas. In particular, gut contents of these two Nemouridae species are analyzed to investigate their role in the functioning of the stream ecosystem.

\section{MATERIALS AND METHODS}

The study was conducted in an Apenninic creek (Torrente Curone, $620 \mathrm{~m}$ a.s.1., 4447'14" N, 904'02" E, northwestern Italy), from April, 2007 to April, 2008. Water temperature was recorded using a HOBO Water Temp Pro datalogger, (Onset Computer Corporation, Bourne, USA) [Q1] and varied notably from $0.01{ }^{\circ} \mathrm{C}$ to $22.3^{\circ} \mathrm{C}$. The stream has dense riparian vegetation, mainly composed of Carpinus betulus, Fraxinus sp., Acer spp., Salix spp. and Quercus pubescens. It presents coarse riverbed with immovable elements, fast flowing waters, a mean depth of $20 \mathrm{~cm}$ and a mean width of $5 \mathrm{~m}$, and elevated slope. Main physico-chemical parameters recorded during the study period are reported in Table[Q2] 1.

During field activities, specimens were collected using a kick net (mesh of $250 \mu \mathrm{m}$ ), sorted and preserved in $75 \%$ ethanol. In the laboratory all nymphs were identified, counted, and total length was measured using a Nikon SMZ 1500 stereomicroscope (0.1 mm accuracy; Nikon, Tokyo, Japan[Q3]) with a SONY HD AVCHD videocamera (Sony Corporation, Tokyo, Japan[Q4]) linked to a Samsung 36" LCD (Samsung, Budapest, Hungary[Q5]).

\begin{tabular}{|l|l|l|l|}
\hline & Manufacturer, & City & Country \\
\hline $\begin{array}{l}\text { HOBO Water Temp Pro } \\
\text { datalogger. }\end{array}$ & Onset Computer Corporation & Bourne, MA & USA \\
\hline $\begin{array}{l}\text { SONY HD AVCHD } \\
\text { videocamera }\end{array}$ & Sony Corporation, & Tokyo, & Japan \\
\hline Samsung 36" LCD & Samsung & Budapest & Hungary \\
\hline
\end{tabular}

Gut contents were analyzed with the methods proposed by Bello and Cabrera (1999), widely used in stonefly 
feeding studies (e.g. Cammarata et al. 2007; López-Rodríguez et al. 2009a). Each individual was placed in a vial with Hertwigs' liquid [Q6] and heated in an oven at $65^{\circ} \mathrm{C}$ for approximately $24 \mathrm{~h}$ before mounting individuals on slides for study under the microscope. A compound microscope equipped with an ocular micrometer was used to estimate the percentage absolute gut content (at $40 \times$ as $\%$ total area occupied by the contents in the whole digestive tract) and the relative abundances of food items in the gut content (at $400 \times$ as $\%$ area occupied by each component of the total gut contents). Mean, standard deviation, minimum and maximum were calculated. Species were classified to functional feeding groups (FFG, sensu Merritt \& Cummins 1996) on the basis of their food sources and mechanisms of food acquisition.

Kendall's tau was used to study the correlation between total length and percentage of gut contents, because it is the most appropriate correlation test when there are a large number of observations, as in the present study. As diet components are dependent on each other, a Holm's adjustment of $P$-values was applied. Mann-Whitney $U$ was used to evaluate possible differences in the percentage of each trophic resource between species. Holm's adjustment of $P$ values was applied in this analysis also.

Statistical analyses were performed with R software (R Development Core Team 2009).

\section{RESULTS}

A total of 283 individuals (102 of $N$. hesperiae and 181 of A. sulcicollis) were measured and processed for gut content analyses. For both species, all nymphal stages were represented. The numbers of individuals belonging to different size classes are shown in Figure[Q7] 1.

Seventy-four nymphs of $N$. hesperiae had some content in their guts. The main trophic resource was coarse particulate organic matter (CPOM), together with detritus[Q8] (Fig. 2). Other minor components of the diet were fungi hyphae and spores. In only one individual indeterminate animal matter was found. Larger nymphs seemed to feed more on CPOM, while smaller fed mainly on detritus, though correlations were very low in every case[Q9] (Table 2).

On the other hand, 127 nymphs of A. sulcicollis had some gut content. They fed mainly on detritus and CPOM, but also on fungi hyphae and spores, and in only one individual algae were found. Also in this species a shift of diet with size was detected. Larger nymphs fed more on detritus and less on fungi spores, but correlation values were low (Table 2).

Differences between species ( $\mathrm{N}$ for $N$. hesperiae $=74$ and $\mathrm{N}$ for A. sulcicollis $=127$ ) regarding each diet component showed significant results for detritus (Mann-Whitney $U=2460.5, P<0.05$ ), CPOM (Mann-Whitney $U=3406.0, P<0.05$ ) and fungi spores (Mann-Whitney $U=2511.0, P<0.05$ ).

\section{DISCUSSION}

Knowledge of specific aspects of the feeding behaviour and feeding requirements of animals is indispensable in acquiring an insight into the competition, coexistence of similar species, availability of food and niche overlapping (Monakov 2003).

In this study the feeding habits of $N$. hesperiae have been investigated for the first time. The results showed that this endemic Italian species behaves mainly as shredder, and secondly as collector-gatherer (sensu Merritt \& Cummins 1996). A shift in resource ingestion was detected in relation to size: larger nymphs acquired more CPOM than smaller. An ontogenetic shift in diet was reported in some other Nemouridae (such as N. lacustris Pictet, 1865 (López-Rodríguez \& Tierno de Figueroa 2005)) and also in other stonefly families, such as Perlodidae (LópezRodríguez et al. 2009b) and Perlidae (Bo \& Fenoglio 2005). As previously pointed out, no other studies exist on this taxon. Nevertheless, available data exist on other congeneric species. All studied Nemoura are phytophagousdetritivorous (as pointed out for Nemouridae in general (Hynes 1976)), some of them acting almost exclusively as collector-gatherers, and others, at different rates, as scraper and/or shredder (e.g. Brittain 1973; Bird \& Kaushik 1985; Azzouz \& Sánchez-Ortega 2000; López-Rodríguez \& Tierno de Figueroa 2005; Silveri et al. 2008). Our results confirm these findings, showing that Nemoura nymphs can be considered quite generalist, acting indistinctly as shredders of large vegetal fragments and as collectors of fine detritus. This role in coarse and fine particle metabolism lets us suppose that these stoneflies have a great importance in the energetic balance of small lotic systems.

In the studied area, the diet of A. sulcicollis was composed mainly of fine detritus and, in a lower concern, of CPOM. Thus the nymphs of this species were mainly collector-gatherers, but also shredders. Also in this species, a change of diet in relation with size was observed: larger nymphs fed more on detritus and less on fungi spores, though the ingestion of less spores is probably an indirect consequence of less ingestion of the substrate where the spores are found, mainly CPOM. 
These results support the detritivorous behaviour previously reported by Madsen (1974) for A. sulcicollis, who also pointed out that nymphs ingested a great quantity of fungi. Nevertheless, the results do not sustain the results found in some other studies (Hynes 1941, 1961; Brinck 1949), where the species is recorded as mainly herbivorous. More recently some authors (Murphy \& Giller 2000; Dangles 2002; Collen et al. 2004; Pretty et al. 2005) considered A. sulcicollis principally as shredder.

Though both species had similar size, nymphal development duration and coexisted in time, their main trophic resource was different, so probably no niche overlapping exists in this mainly oligotrophic system, but further studies are needed to confirm this hypothesis.

Moreover, the studied species had significant differences in the percentage of their main diet components, supporting the different use they do of their main feeding resources, and also supporting their classification in different FFG.

In conclusion, this work supports what has been previously pointed out by Stewart and Stark (2002), i.e. that the feeding habits of an unstudied species cannot be inferred from studies of congeners. Even intraspecific differences in diet and ontogenetic variations are frequently found in this order of insects. Thus, as suggested also by Mihuc and Minshall (1995), functional feeding groups should be used with caution to infer systems-level trophic dynamics in streams and rivers, though they are very useful in ecological studies.

\section{ACKNOWLEDGMENTS}

The authors thank M. Pessino, M. Cammarata, and M. Grenna for their help during field sampling, M. Bottaro for his help in the laboratory and Dr A. González Megías for her statistical suggestions. This study was supported by Provincia di Alessandria ATF grants.

\section{REFERENCES}

Azzouz M, Sánchez-Ortega A (2000) Feeding of the nymphs of nine stonefly species (Insecta, Plecoptera) from North Africa (Rif Mountain, Morocco). Zoologica Baetica $11,35-50$.

Bello CL, Cabrera MI (1999) Uso de la técnica microhistológica de Cavender y Hansen en la identificación de insectos acuáticos. Boletín Entomológico Venezolano 14, 77-79.

Bird GA, Kaushik NK (1985) Processing of elm and maple leaf discs by collectors and shredders in laboratory feeding studies. Hydrobiologia 126, 109-120.

Bo T, Fenoglio S (2005) Age-related shift in the diet of Perla marginata in a woodland Apenninic creek of NW Italy (Plecoptera : Perlidae). Entomologia Generalis 28, 147154.

Bo T, Fenoglio S, López-Rodríguez MJ, Tierno de Figueroa JM (2009) Phenology of adult Stoneflies (Plecoptera) of the Curone stream (Northern Apennines, Italy). Journal of Freshwater Ecology 24, 279-283.

Brinck P (1949) Studies on Swedish stoneflies (Plecoptera). Opuscula Entomologica Suppl. 11, 1-250.

Brittain JE (1973) The biology and life cycle of Nemoura avicularia Morton (Plecoptera). Freshwater Biology 3, 199-210.

Cammarata M, Fenoglio S, López-Rodríguez MJ, Bo T, Tierno de Figueroa JM (2007) Prey selection of Perla grandis (Rambur, 1841) nymphs (Plecoptera : Perlidae) in Borbera stream (NW, Italy). Boletín de la Sociedad Entomológica Aragonesa 41, 271274.

Collen P, Keay EJ, Morrison BRS (2004) Processing of pine (Pinus sylvestris) and birch (Betula pubescens) leaf material in a small river system in the northern Cairngorms, Scotland. Hydrology and Earth System Sciences 8, 567-577. 
Dangles O (2002) Aggregation of shredder invertebrates associated with benthic detrital pools in seven headwater forested streams. Verhandlungen der Internationalen Vereinigung für theoretische und angewandte Limnologie 28, 1-4.

Fenoglio S, Bo T (2009) Lineamenti Di Ecologia Fluviale. De Agostini Città Studi Ed., Novara.

Fochetti R, Tierno de Figueroa JM (2008a) Global diversity of stoneflies (Plecoptera; Insecta) in freshwater. Hydrobiologia 595, 365-377.

Fochetti R, Tierno de Figueroa JM (2008b) Plecoptera. Fauna d'Italia. Edizioni Calderini de Il Sole 24 ore, Milano.

Hynes HBN (1941) The taxonomy and ecology of the nymphs of British Plecoptera with notes on the adults and eggs. Transactions of the Royal Entomological Society of London 91, 459-557.

Hynes HBN (1961) The invertebrate fauna of a Welch mountain stream. Archiv für Hydrobiologie 57, 344-388.

Hynes HBN (1976) Biology of Plecoptera. Annual Review of Entomology 21, 135-153.

López-Rodríguez MJ, Tierno de Figueroa JM (2005) Ciclo de vida y composición de la dieta de Nemoura lacustris Pictet, 1865 (Plecoptera, Nemouridae). Boletín de la Asociación española de Entomología 29, 87-97.

López-Rodríguez MJ, Tierno de Figueroa JM, Alba-Tercedor J (2009a) Life history, feeding and secondary production of two Nemouroidea species (Plecoptera, Insecta) in a temporary stream of Southern Iberian Peninsula. Fundamental and Applied Limnology (Archiv für Hydrobiologie) 175, 161-170.

López-Rodríguez MJ, Tierno de Figueroa JM, Fenoglio S, Bo T, Alba-Tercedor J (2009b) Life strategies of 3 Perlodidae species (Plecoptera) in a Mediterranean seasonal stream in southern Europe. Journal of the North American Benthological Society 28, 611-625.

Madsen BL (1974) A note on the food of Amphinemura sulcicollis. Hydrobiologia 45, $169-175$.

Merritt RW, Cummins KW (1996) An Introduction to the Aquatic Insects of North America, 3rd edn, Kendall/Hunt, Dubuque.

Mihuc TB, Minshall GW (1995) Trophic generalists versus trophic specialists: implications for food web dynamics in post-fire streams. Ecology 76, 2361-2372.

Monakov AV (2003) Feeding of Freshwater Invertebrates. Kenobi Productions, Ghent.

Murphy JF, Giller PS (2000) Seasonal dynamics of macroinvertebrate assemblages in the benthos and associated with detritus packs in two low-order streams with different riparian vegetation. Freshwater Biology 43, 617-631.

Pretty JL, Giberson DJ, Dobson M (2005) Resource dynamics and detritivore production in an acid stream. Freshwater Biology 50, 578-591.

R Development Core Team (2009) R: A Language and Environment for Statistical Computing. R Foundation for Statistical Computing, Vienna. [Cited •.. •.• [Q10].] Available from URL: http://www.R-project.org[Q11]. 
Silveri L, Tierno de Figueroa JM, Maiolini B (2008) Notes on the nymphal biology of Nemoura mortoni Ris 1902 (Plecoptera, Nemouridae) in a high altitude stream

(Trentino, Italian Alps). Zoologica Baetica 19, 51-56.

Stewart KW, Stark BP (2002) Nymphs of North American Stonefly Genera (Plecoptera), 2nd edn, Caddis Press, Columbus.

Tierno de Figueroa JM, Bo T, López-Rodríguez MJ, Fenoglio S (2009) Life cycle of three stonefly species (Plecoptera) from an Apenninic stream (Italy) with the description of the nymph of Nemoura hesperiae. Annales de la Société Entomologique de France 45, 339-343.

Figure 1 Total number of individuals and number of individuals with some gut contents belonging to the different size classes in Nemoura hesperiae and Amphinemura sulcicollis.

Figure 2 Histogram showing relative importance of the different components in the diet of Nemoura hesperiae and Amphinemura sulcicollis (mean $\pm \mathrm{SD}$ ).

Table 1 Main physico-chemical parameter recorded in the study site during the sampling period (mean \pm SD)

\begin{tabular}{|l|l|}
\hline Parameter & Values \\
\hline Conductivity $(\mu \mathrm{S} / \mathrm{cm})$ & $330.0 \pm 13.3$ \\
\hline Dissolved oxygen $(\mathrm{mg} / \mathrm{l})$ & $7.95 \pm 0.13$ \\
\hline $\mathrm{pH}$ & $8.97 \pm 0.22$ \\
\hline Flow speed $(\mathrm{m} / \mathrm{s})$ & $0.67 \pm 0.14$ \\
\hline
\end{tabular}

Table 2 Kendall tau correlations between total length and diet components of the studied species

\begin{tabular}{|l|l|l|}
\hline & Nemoura hesperiae total length & Amphinemura sulcicollis total length \\
\hline$\%$ detritus & $-0.229^{*}$ & $0.156^{*}$ \\
\hline$\%$ CPOM & $0.244^{*}$ & -0.125 \\
\hline$\%$ hyphae & -0.054 & -0.068 \\
\hline$\%$ animal matter & -0.183 & $-0.235^{*}$ \\
\hline$\%$ algae & 0.151 & - \\
\hline
\end{tabular}

*Statistically significant at $P<0.05$, after Holm's adjustment. 